Polymer Journal, Vol. 38, No. 8, pp. 814-818 (2006)

(C) 2006 The Society of Polymer Science, Japan

\title{
Physical Aging and Refractive Index of Poly(methyl methacrylate) Glass
}

\author{
Norihisa TANIO ${ }^{\dagger}$ and Teruaki NAKANISHI \\ Faculty of Photonics Science and Technology, Chitose Institute of Science and Technology, \\ 758-65 Bibi, Chitose 066-8655, Japan
}

(Received December 13, 2005; Accepted April 19, 2006; Published July 7, 2006)

\begin{abstract}
Physical aging of poly(methyl methacrylate) (PMMA) glass was studied by refractive index measurement. We measured change of refractive index of PMMA glass with annealing at temperatures below the glass transition temperature $\left(T_{\mathrm{g}}\right)$ by optical prism coupling, and determined volume relaxation by physical aging using the Lorentz-Lorenz equation. In this paper, the effect of aging temperature on volume relaxation of PMMA glass was investigated. Maximum volume relaxation for PMMA glass was determined at $18^{\circ} \mathrm{C}$ below the $T_{\mathrm{g}}$. [doi:10.1295/polymj.PJ2005192]

KEY WORDS Polymer Glass / Physical Aging / Refractive Index / Prism Coupling / Volume Relaxation / Glass Transition Temperature / Poly(methyl methacrylate) /
\end{abstract}

Amorphous polymer glasses are essentially in thermodynamic non-equilibrium states. Physical aging ${ }^{1}$ describes the time dependence of change in the behavior of a polymer glass held at temperatures below the glass transition. Such change is normally the result of continuous slow relaxation of the glass from its initial non-equilibrium state towards the final thermodynamic equilibrium state. Thermodynamical properties such as volume $e^{2,3}$ or enthalpy ${ }^{4,5}$ have been mainly considered for the study of this phenomenon. After a quench into the glassy state, the polymer shows a continuous decrease of the specific volume with time, which leads to a decrease in free volume and thus of mobility of the polymer molecules. This change of mobility of the molecular segments is assumed to be the origin of the change in dynamic mechanical properties during aging. ${ }^{6}$ Many other properties of amorphous polymer glasses can be affected by aging. Recently, we reported the change of refractive indices of low-loss PMMA glass with annealing at temperatures below the glass transition temperature $\left(T_{\mathrm{g}}\right)$, and tried to determine the volume relaxation by physical aging. ${ }^{7}$ In this paper, the effect of aging temperature on volume relaxation of PMMA glass was investigated by prism coupling method. Prism coupling is convenient and accurate for detecting refractive index.

\section{EXPERIMENTAL}

\section{Preparation of PMMA Glass}

In this study, highly purified PMMA glass was used for measurements. After ordinary purification of methyl methacrylate (MMA) monomer with a distillation (bp $46-47^{\circ} \mathrm{C} / 100 \mathrm{mmHg}$ ) and $0.2 \mu \mathrm{m}$ mem- brane filter, rigorous purification was carried out as follows: Ampoule A with distilled MMA monomer was connected with two ampoules B and C carefully purified. Here, di-tert-butyl peroxide (DBPO) as an initiator and $n$-butyl mercaptan $(n \mathrm{BM})$ as a chain transfer agent were placed in ampoule $B$, and ampoule $C$ was empty. Ampoules A and B were frozen with liquid nitrogen, evacuated, and substituted by nitrogen. The MMA monomer, DBPO, and $n \mathrm{BM}$ were degassed by several freeze-thaw cycles, and slowly distilled into the ampoule $\mathrm{C}$ under vacuum by cooling ampoule $\mathrm{C}$ with liquid nitrogen. Ampoule $\mathrm{C}$ was sealed under vacuum and immersed in silicone oil for polymerization. After polymerization, the cylindrical PMMA sample with a $20 \mathrm{~mm}$ diameter was removed from ampoule $\mathrm{C}$ for measurement. In this study, PMMA sample (weight-average molecular weight: $M_{\mathrm{w}}=7.0 \times 10^{4}$, remaining monomer $=1.2 \mathrm{wt} \%$ ) was polymerized at $130^{\circ} \mathrm{C}$ for $96 \mathrm{~h}$ and the weight percentages of DBPO and $n \mathrm{BM}$ were each $0.20 \mathrm{wt} \%$.

\section{Enthalpy Relaxation Measurement}

Enthalpy relaxation of PMMA glass was measured by DSC (Shimadzu Co., DSC-50). The weight of PMMA sample for DSC measurement was about $5 \mathrm{mg}$. The following standard thermal history was employed for the PMMA sample:

1) To eliminate the effects of previous thermal history after polymerization, the PMMA sample was annealed at $110^{\circ} \mathrm{C}$ for $3 \mathrm{~h}$.

2) The PMMA sample was annealed for an aging time of $t_{\mathrm{a}}$ at chosen aging temperatures $\left(T_{\mathrm{a}}\right)$.

3) The PMMA sample was quenched down to the room temperature.

${ }^{\dagger}$ To whom correspondence should be addressed (E-mail: n-tanio@photon.chitose.ac.jp). 
4) DSC measurements were carried out with increasing temperature from room temperature to $170^{\circ} \mathrm{C}$ at a heating rate of $10^{\circ} \mathrm{C} \mathrm{min}^{-1}$.

\section{Light Scattering Measurement}

Light scattering measurements were made with light scattering spectrophotometer (Otsuka Electronics, DLS-7000). The cylindrical PMMA sample with a $20 \mathrm{~mm}$ diameter was placed in the center of the cylindrical glass cell. The gap between the sample and inner wall of the glass cell was filled with immersion oil with a refractive index of 1.5 . This glass cell was perpendicularly located at the center of the goniometer, and a parallel beam of vertically polarized $\mathrm{He}-\mathrm{Ne}$ laser (wavelength $\lambda_{0}=633 \mathrm{~nm}$ ) was injected from the side. In this paper, polarized $\left(V_{\mathrm{V}}\right)$ and depolarized $\left(H_{\mathrm{V}}\right)$ scattered intensities were measured at room temperature. Here the letters $H$ and $V$ (or v) denote horizontal and vertical polarization, respectively, and the upper case letter and the subscript letter denote the scattered light and the incident beam, respectively. To estimate the absolute intensity, pure toluene was used as a standard for calibration. The measurement error of the scattering intensity $\left(V_{\mathrm{V}}\right.$ or $\left.H_{\mathrm{V}}\right)$ in the order of $10^{-8} \mathrm{~cm}^{-1}$ was less than $2 \%$.

\section{Refractive Index Measurement}

Refractive indices of PMMA glasses were determined with prism coupler (Metricon model 2010 prism coupler). The cylindrical PMMA sample with a $20 \mathrm{~mm}$ diameter and a $2 \mathrm{~mm}$ thickness was used for the measurement. For bulk material index measurement, the principle of operation is resembles closely the operation of the Abbe refractometer. If a material with refractive index $n$ is brought into intimate contact with a prism with index $n_{\mathrm{p}}$, laser light directed into the base of the prism will be totally reflected at the prism base until the angle of incidence $\theta$ becomes less than the critical angle $\theta_{\mathrm{c}}$ where

$$
\theta_{\mathrm{c}}=\sin ^{-1}\left(\frac{n}{n_{\mathrm{p}}}\right)
$$

$\theta_{\mathrm{c}}$ is easily measured using the detector in Figure 1 since the detector intensity drops abruptly as $\theta$ drops below the critical angle and light starts to leak into the bulk material. Since $n_{\mathrm{p}}$ is known, $n$ can then be determined from eq 1 . Prism coupling ${ }^{8,9}$ is convenient and refractive index change as small as $10^{-4}$ can be measured. A TE polarized He-Ne laser (wavelength $633 \mathrm{~nm}$ ) was used to monitor the refractive indices.

\section{Other Measurements}

The molecular weight was measured by gel permeation chromatography (GPC) with chloroform as a carrier. The weight percentage of the remaining

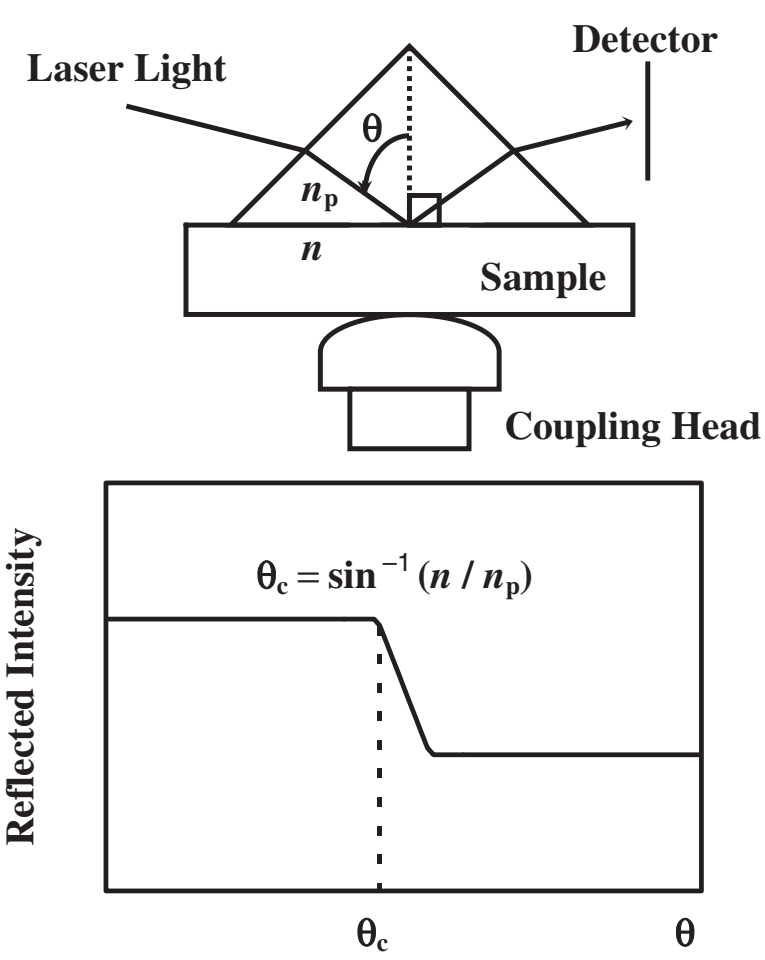

Figure 1. Prism coupling method for refractive index measurement.

monomer in the PMMA bulk was measured as follows: The polymer sample was dissolved in a small amount of acetone, after which methanol was added to precipitate the polymer. The monomer concentration in the supernatant solution was determined by gas chromatography. Then, the weight percentage of the monomer was calculated.

\section{RESULTS AND DISCUSSION}

PMMA glass is a common optical amorphous polymer and has been already used as a core material of polymer optical fiber. We demonstrated that the light scattering loss of PMMA glasses, even in using contaminant-free monomer varied widely with polymerization and heat-treatment conditions. ${ }^{10-14}$ PMMA glasses polymerized below the $T_{\mathrm{g}}$ had excess scattering loss (hundreds $\mathrm{dB} \mathrm{km}^{-1}$ ) due to large-size (several hundreds $\AA$ ) heterogeneous structure with the order of $10^{-5}-10^{-4}$ of refractive-index difference. It was experimentally and theoretically clarified that this fluctuation is caused mainly by the isotropic strain inhomogeneities created during polymerization, and not by the small amount of remaining monomers or additives, the molecular weight of the polymers, the stereoregularity due to the specific tacticity of PMMA, nor crosslinking as a result of the gel effect. ${ }^{10}$ On the other hand, with polymerization at $130^{\circ} \mathrm{C}$ (above the $T_{\mathrm{g}}$ ), no angular dependence was observed and the isotropic light scattering loss was reduced to $9.7 \mathrm{~dB} \mathrm{~km}^{-1}$ 
(at $633 \mathrm{~nm}$ ) which is close to the value predicted by the thermally induced fluctuation theory. ${ }^{15}$ Using the fluctuation theory, the intensity of the isotropic light scattering $\left(V_{\mathrm{V}}{ }^{\text {iso }}\right)$ from thermally induced density fluctuations in a structureless liquid is

$$
V_{\mathrm{V}}{ }^{\text {iso }}=\frac{\pi^{2}}{9 \lambda_{0}{ }^{4}}\left(n^{2}-1\right)^{2}\left(n^{2}+2\right)^{2} k T \beta
$$

where $\lambda_{0}$ is the wavelength of light in vacuum, $k$ is the Boltzmann constant, $T$ is the absolute temperature, $n$ is the refractive index and $\beta$ is the isothermal compressibility. The fluctuation theory for structureless liquids indicates that according to eq 2 , the isotropic scattering loss decreases with the decrease in isothermal compressibility and refractive index. The value of $V_{\mathrm{V}}{ }^{\text {iso }}$ calculated using the value of $\beta$ at $T_{\mathrm{g}}$ according to a frozen model showed good agreement with the observed value for PMMA glass. When the reported $\beta$ value $^{16}$ at $100{ }^{\circ} \mathrm{C}$ (near $T_{\mathrm{g}}$ ) is used in eq 2 the calculated $\alpha^{\text {iso }}$ value is $9.5 \mathrm{~dB} \mathrm{~km}^{-1}$ which is close to our observed value $\left(9.7 \mathrm{~dB} \mathrm{~km}^{-1}\right)$ for PMMA glass polymerized above the $T_{\mathrm{g}}$. Thus, we can say that the glass transition temperature is the critical temperature for determining the excess light scattering of polymer glasses. When polymer glass is polymerized or heattreated above the $T_{\mathrm{g}}$, the excess scattering intensity disappears and the isotropic light scattering loss is reduced to the value calculated from fluctuation theory. Figure 2 shows the isotropic light scattering intensity $\left(V_{\mathrm{V}}\right)$ and anisotropic light scattering intensity $\left(H_{\mathrm{V}}\right)$ at $633 \mathrm{~nm}$ for PMMA glass polymerized at $130^{\circ} \mathrm{C}$. In this study, this low-loss PMMA glass with no large size heterogeneous structure was used for measure-
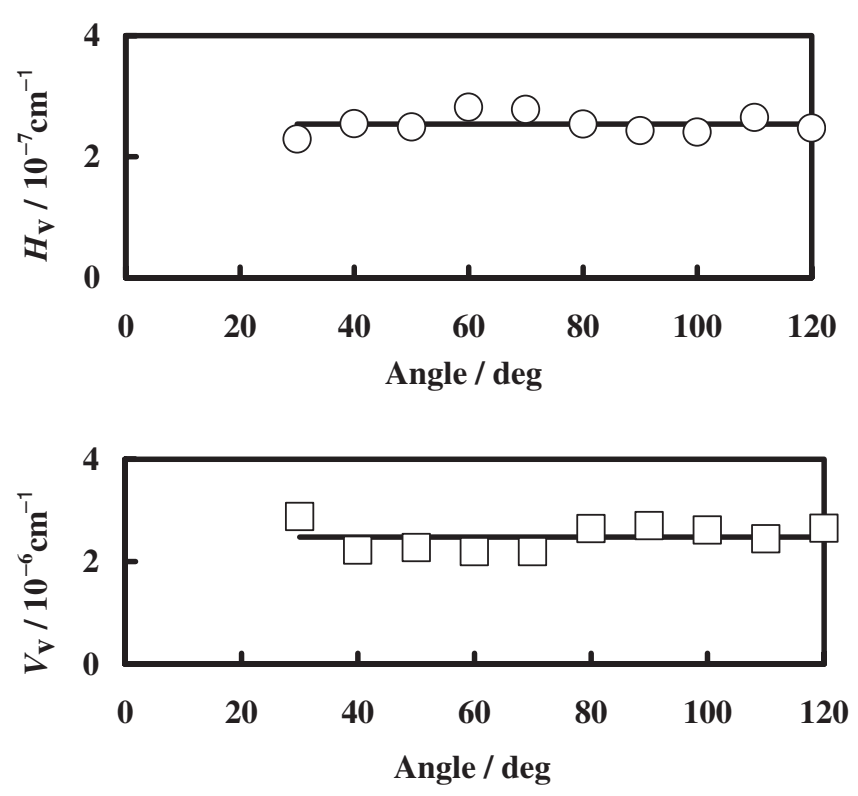

Figure 2. $V_{\mathrm{V}}$ and $H_{\mathrm{V}}$ scattering by PMMA glass polymerized at $130^{\circ} \mathrm{C}$ for $96 \mathrm{~h}$. ments. Recently, we investigated the effects of enthalpy relaxation on light scattering loss of low-loss PMMA glass which had no excess scattering, and concluded that light scattering loss of glassy PMMA is not affected inherently by physical aging. ${ }^{17}$

Heat capacity of a polymer glass undergoes a step change in the glass transition region. We define the glass transition temperature, $T_{\mathrm{g}}$, as the temperature at which the change of heat capacity associated with glass transition is $\Delta C_{p} / 2$, where $\Delta C_{p}$ is the specific heat increment between the liquid and glass states at glass transition region. $T_{\mathrm{g}}$ for unaged PMMA glass was $108^{\circ} \mathrm{C}$.

Physical aging is time- and temperature-dependent. ${ }^{18}$ Most studies on physical aging for amorphous polymers have been performed at temperatures close to $T_{\mathrm{g}}$. We measured the enthalpy relaxation for PMMA glass at aging temperatures, $T_{\mathrm{a}}=70^{\circ} \mathrm{C}$ $\left(=T_{\mathrm{g}}-38^{\circ} \mathrm{C}\right), 80^{\circ} \mathrm{C}\left(=T_{\mathrm{g}}-28^{\circ} \mathrm{C}\right), 90^{\circ} \mathrm{C}\left(=T_{\mathrm{g}}-\right.$ $\left.18^{\circ} \mathrm{C}\right)$ and $100^{\circ} \mathrm{C}\left(=T_{\mathrm{g}}-8^{\circ} \mathrm{C}\right)$. DSC studies of the enthalpy relaxation process for PMMA glasses of different aging times at $90^{\circ} \mathrm{C}$ are illustrated in Figure 3. Aging at $90^{\circ} \mathrm{C}$ produces an endothermic peak at the glass transition temperature. When aging times increase, the endothermic peak increases. From these thermograms, enthalpy relaxation $\Delta H$ can be determined by taking the difference between the curve corresponding to the quenched state and the curves corresponding to different aged states. Figure 4 presents evolution of $\Delta H$ as a function of aging time at various $T_{\mathrm{a}}$ for PMMA glass. With increasing aging time, enthalpy relaxation increased, and reached 1.7, 1.8, 2.9, and $2.1 \mathrm{~J} \mathrm{~g}^{-1}$, at $T_{\mathrm{a}}=70^{\circ} \mathrm{C}, 80^{\circ} \mathrm{C}, 90^{\circ} \mathrm{C}$, and

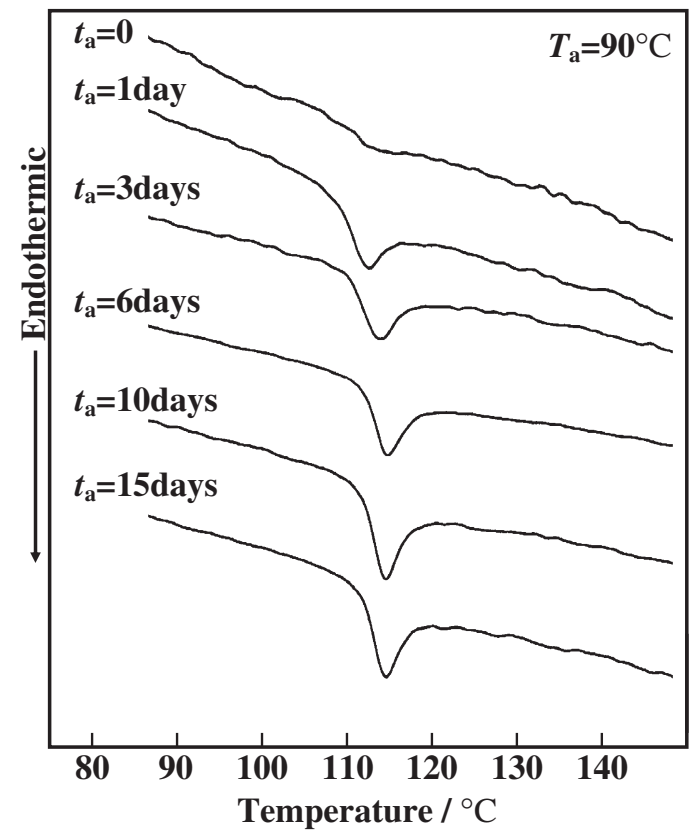

Figure 3. DSC curves of PMMA glass aged at $90^{\circ} \mathrm{C}$. 


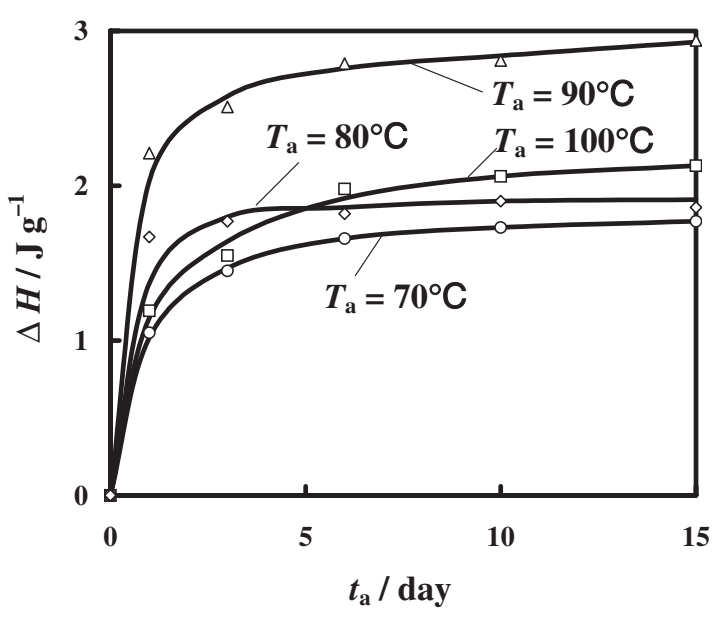

Figure 4. Enthalpy relaxation $(\Delta H)$ plotted as a function of aging time $\left(t_{\mathrm{a}}\right)$ at various aging temperature $\left(T_{\mathrm{a}}\right)$ for PMMA glass.

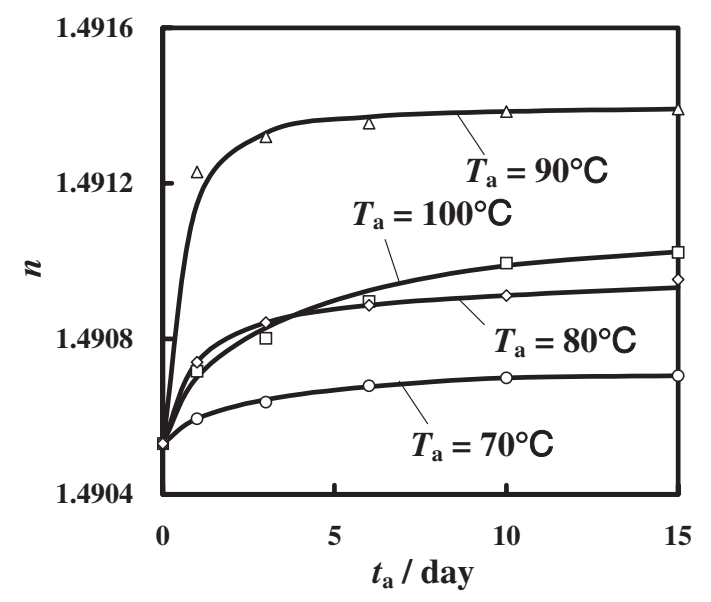

Figure 5. Refractive index $(n)$ at $633 \mathrm{~nm}$ plotted as a function of aging time $\left(t_{\mathrm{a}}\right)$ at various aging temperature $\left(T_{\mathrm{a}}\right)$ for PMMA glass.

$100^{\circ} \mathrm{C}$, respectively. Maximum enthalpy relaxation was determined at $90^{\circ} \mathrm{C}$.

Refractive index measurements were performed with prism-coupler down to room temperature after isothermal aging. Figure 5 shows the refractive index $\left(n_{\mathrm{TE}}\right)$ at $633 \mathrm{~nm}$ as function of aging time at various $T_{\mathrm{a}}$ for PMMA glass. Before aging, $n_{\mathrm{TE}}$ of PMMA was 1.4905 . With increasing aging time, $n_{\mathrm{TE}}$ slightly increased, and reached $1.4907,1.4910,1.4914$, and 1.4910 , at $T_{\mathrm{a}}=70^{\circ} \mathrm{C}, 80^{\circ} \mathrm{C}, 90^{\circ} \mathrm{C}$, and $100^{\circ} \mathrm{C}$, respectively. Maximum enthalpy relaxation was $90^{\circ} \mathrm{C}$. The refractive index change $(\Delta n)$ by aging at $90^{\circ} \mathrm{C}$ for $15 \mathrm{~d}$ is 0.0009 .

The refractive index $(n)$ of a compound can be calculated from its molar refraction and molecular volume using the Lorentz-Lorenz equation, ${ }^{19,20}$

$$
n=\sqrt{\left(2 \frac{[R]}{V}+1\right) /\left(1-\frac{[R]}{V}\right)}
$$

where $[R]$ is molar refraction and $V$, molecular volume. Molar refraction $[R]$ is taken as the sum of atomic refractions. ${ }^{21-23}$

Intrinsic molecular volume $V_{\text {int }}$ of monomer unit for amorphous polymer can be calculated from the atomic radius and bond length of the constituent atoms based on the method developed by Slonimskii et al. ${ }^{24}$ When an atom $\mathrm{A}$ (atomic radius $R$ ) is bound to atom $\mathrm{A}_{\mathrm{i}}$ (atomic radius $R_{\mathrm{i}}$ ) with bond length $d_{\mathrm{i}}$, the atomic volume $\Delta V(\mathrm{~A})$ of atom $\mathrm{A}$ is given by

$$
\begin{aligned}
\Delta V(\mathrm{~A}) & =(4 / 3) \pi R^{3}-\sum_{\mathrm{i}}(1 / 3) \pi h_{\mathrm{i}}^{2}\left(3 R-h_{\mathrm{i}}\right) \\
h_{\mathrm{i}} & \equiv R-\left(R^{2}+d_{\mathrm{i}}^{2}-R_{\mathrm{i}}^{2}\right) /\left(2 d_{\mathrm{i}}\right)
\end{aligned}
$$

If the molecule consists of atoms $A_{1}-A_{j}$, the intrinsic molecular volume $V_{\text {int }}$ is given by

$$
V_{\text {int }}=N_{\mathrm{A}} \sum_{\mathrm{j}} \Delta V\left(\mathrm{~A}_{\mathrm{j}}\right)
$$

where $N_{\mathrm{A}}$ is Avogadro's number. The actual molecular volume $(V)$ of the monomer unit is expressed as

$$
V=\frac{V_{\text {int }}}{K}
$$

where $K$ is the packing coefficient ${ }^{21-23}$ of the molecule. The specific volume $(v)$ of polymer is given by

$$
v=\frac{V_{\text {int }}}{K M_{0}}
$$

where $M_{0}$ is molecular weight of a monomer unit.

The specific volume of amorphous polymer can be estimated if packing coefficients are given. Packing coefficient $(K)$ dependence of the refractive indices of the compounds can be calculated using above equations. Figure 6 shows refractive indices at $633 \mathrm{~nm}$ for PMMA as function of packing coefficients. Before

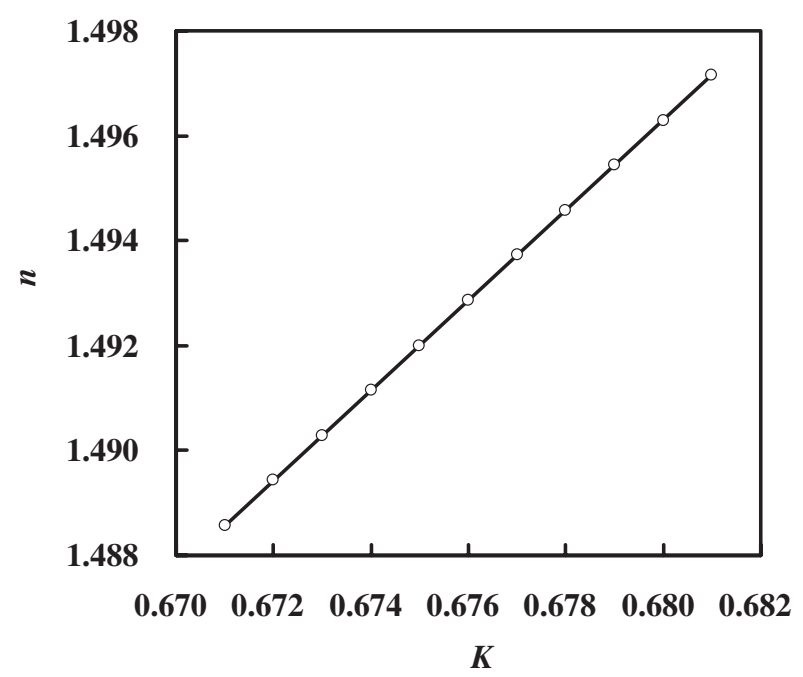

Figure 6. Packing coefficient $(K)$ dependence of the refractive index $(n)$ of PMMA. 


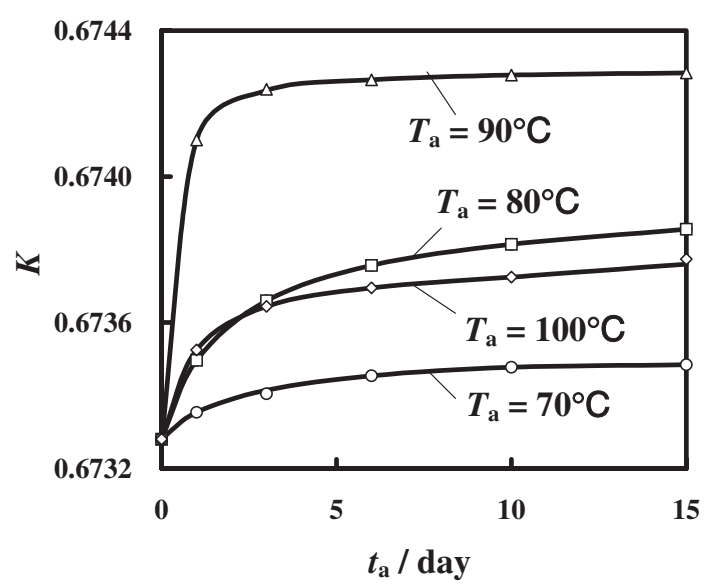

Figure 7. Packing coefficient $(K)$ as function of aging time $\left(t_{\mathrm{a}}\right)$ at various aging temperature $\left(T_{\mathrm{a}}\right)$ for PMMA glass.

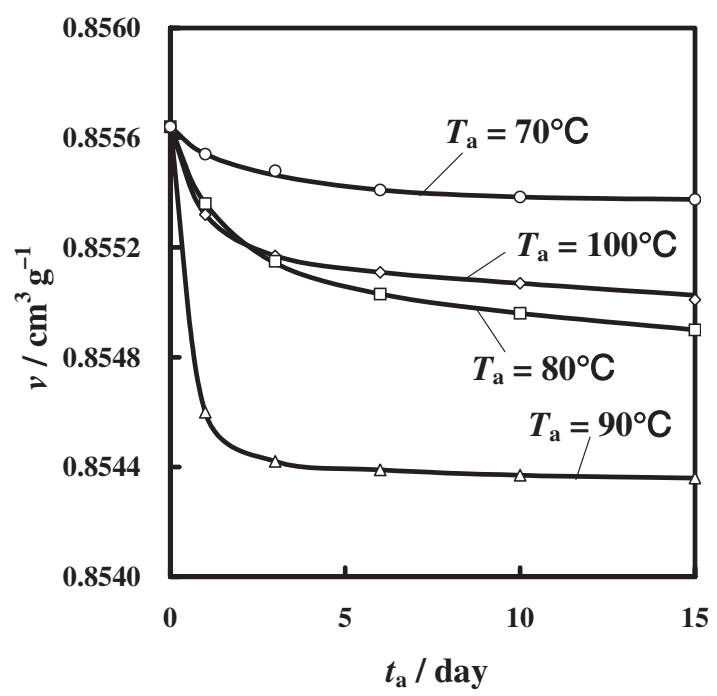

Figure 8. Specific volume $(v)$ as function of aging time $\left(t_{\mathrm{a}}\right)$ at various aging temperature $\left(T_{\mathrm{a}}\right)$ for PMMA glass.

annealing the refractive index was 1.4905 by a prism coupler, indicating that the packing coefficient $K$ is 0.6733 . Figure 7 shows the change of packing coefficient of PMMA with annealing from the data of Figure 5. Figure 8 is the calculated specific volume as function of annealing time for PMMA from the $K$ using eq 7. The specific volume decreased with aging time. Before aging, specific volume was 0.8556 $\mathrm{cm}^{3} \mathrm{~g}^{-1}$. With increasing time, specific volume decreased, reaching $0.8544 \mathrm{~cm}^{3} \mathrm{~g}^{-1}$ at $90^{\circ} \mathrm{C}$. The specific volume change $(\Delta v)$ by aging at $90^{\circ} \mathrm{C}$ for $15 \mathrm{~d}$ is $1.2 \times 10^{-3}$. Maximum volume relaxation for PMMA glass was determined at $18^{\circ} \mathrm{C}$ below the $T_{\mathrm{g}}$. Volume relaxation measurements of amorphous poly- mers were carried out by Schwarzl, ${ }^{3}$ and relaxation behavior is discussed by the curves of relaxation rate as a function of aging temperature. The maximum relaxation rate was determined at about $20^{\circ} \mathrm{C}$ below the $T_{\mathrm{g}}$ for polystyrene and polycarbonate.

\section{CONCLUSION}

Isothermal aging has been carried out on PMMA glass at various temperatures below the $T_{\mathrm{g}}$. The effect of aging temperature on volume relaxation of PMMA glass was investigated. We measured change of refractive index of PMMA glass and determined volume relaxation by physical aging using the Lorentz-Lorenz equation. Maximum volume relaxation for PMMA glass was determined at $18^{\circ} \mathrm{C}$ below the $T_{\mathrm{g}}$.

\section{REFERENCES}

1. L. C. E. Struik, "Physical Aging in Amorphous Polymers and Other Materials", Elsevier, Amsterdam, 1978.

2. A. J. Kovacs, J. Polym. Sci., 30, 131 (1958).

3. R. Greiner and F. R. Schwarzl, Rheol. Acta, 23, 378 (1984).

4. H. Yoshida and Y. Kobayashi, Polym. J., 14, 925 (1982).

5. J. M. G. Cowie and R. Ferguson, Polymer, 34, 2135 (1993).

6. S. E. B. Petrie, J. Macromol. Sci., Part B: Phys., 12, 225 (1976).

7. N. Tanio, Polym. J., 34, 466 (2002).

8. P. K. Tien, Appl. Opt., 10, 2395 (1971).

9. T. N. Ding and E. Garmire, Appl. Opt., 22, 3177 (1983).

10. Y. Koike, N. Tanio, and Y. Ohtsuka, Macromolecules, 22, 1367 (1989).

11. N. Tanio, Y. Koike, and Y. Ohtsuka, Polym. J., 21, 119 (1989).

12. N. Tanio, Y. Koike, and Y. Ohtsuka, Polym. J., 21, 259 (1989).

13. N. Tanio and Y. Koike, Kobunshi Ronbunshu, 53, 682 (1996).

14. N. Tanio, Kobunshi Ronbunshu, 61, 12 (2004).

15. A. Einstein, Ann. Phys., 33, 1275 (1910).

16. K. H. Hellwege, W. Knappe, and P. Lehmann, Kolloid Z. Z. Polym., 183, 110 (1962).

17. N. Tanio, H. Kato, Y. Koike, H. E. Bair, S. Matsuoka, and L. L. Blyler, Jr., Polym. J., 30, 56 (1998).

18. E. Muzeau, G. Vigier, and R. Vassoille, J. Non-Cryst. Solids, 172-174, 575 (1994).

19. H. A. Lorentz, Ann. Phys., 9, 641 (1880).

20. L. V. Lorenz, Ann. Phys., 11, 70 (1880).

21. N. Tanio and M. Irie, Jpn. J. Appl. Phys., 33, 3942 (1994).

22. N. Tanio and Y. Koike, Jpn. J. Appl. Phys., 36, 743 (1997).

23. N. Tanio and Y. Koike, Polym. J., 32, 43 (2000).

24. G. L. Slonimskii, A. A. Askadskii, and A. I. Kitaigorodskii, Vysokomol. Soedin., Ser. A, 12, 494 (1970). 